\title{
Costs of Parkinson's Disease in a Privately Insured Population
}

\author{
Scott J. Johnson • Anna Kaltenboeck • Melissa Diener • \\ Howard G. Birnbaum • ElizaBeth Grubb • \\ Jane Castelli-Haley $\cdot$ Andrew D. Siderowf
}

Published online: 2 August 2013

(c) The Author(s) 2013. This article is published with open access at Springerlink.com

\begin{abstract}
Background This is the first analysis to estimate the costs of commercially insured patients with Parkinson's disease (PD) in the USA. Prior analyses of PD have not examined costs in patients aged under 65 years, a majority of whom are in the workforce.

Objective Our objective was to estimate direct and indirect costs associated with PD in patients under the age of 65 years who are newly diagnosed or have evidence of advanced PD. Methods PD patients were selected from a commercially insured claims database $(N>12,000,000 ; 1999-2009)$; workloss data were available for a sub-sample of enrollees. Newly diagnosed patients with evidence of similar disorders were excluded. Patients with evidence of advanced PD disease, including ambulatory assistance device users (PDAAD) and institutionalized (PDINST) patients, as well as newly diagnosed PD patients, were analyzed. Each PD cohort was age-, gender- and region-matched to controls without PD. Direct (i.e. insurer payments to providers) and indirect (i.e. workloss) costs were reported in \$US, year
\end{abstract}

S. J. Johnson, A. D. Siderowf and J. Castelli-Haley: Affiliation at the time of research.

S. J. Johnson · H. G. Birnbaum

Analysis Group, Inc., Boston, MA, USA

A. Kaltenboeck $(\bowtie) \cdot$ M. Diener

Analysis Group, Inc., 10 Rockefeller Plaza, 15th Floor,

New York, NY 10020, USA

e-mail: akaltenboeck@analysisgroup.com

E. Grubb · J. Castelli-Haley

Teva Neuroscience, Kansas City, MO, USA

A. D. Siderowf

Department of Neurology, University of Pennsylvania,

Philadelphia, PA, USA
2010 values, and were descriptively compared using Wilcoxon rank sum tests.

Results Patients had excess mean direct PD-related costs of $\$ \mathrm{US} 4,072(p<0.001 ; N=781)$ in the year after diagnosis. The PDAAD cohort $(N=214)$ had excess direct PD-related costs of $\$$ US26,467 $(p<0.001)$ and the PDINST cohort $(N=156)$ had excess direct PD-related costs of $\$$ US37,410 $(p<0.001)$ in the year after entering these states. Outpatient care was the most expensive cost source for newly diagnosed patients, while inpatient care was the most expensive for PDAAD and PDINST patients. Excess indirect costs were \$US3,311 $(p<0.05 ; N=173)$ in the year after initial diagnosis.

Conclusions Direct costs for newly diagnosed PD patients exceeded costs for controls without PD, and increased with PD progression. Direct costs were approximately 6-7 times higher in patients with advanced PD than

\section{Key Points for Decision Makers}

- This is the first analysis to estimate the costs of commercially insured patients with Parkinson's disease (PD) in the USA, stratified by claims-data proxy indicators of disease progression.

- Direct costs related to PD are substantial and grow with disease progression. While newly diagnosed patients incur approximately double the direct costs of their matched controls, patients requiring an ambulatory assistance device and institutionalization incurred six and seven times the direct costs of their matched controls, respectively.

- Indirect costs represent a substantial portion of total costs; in the year after diagnosis, indirect costs represented $45 \%$ of total costs. 
in matched controls. Indirect costs represented $45 \%$ of total excess costs for newly diagnosed PD patients.

\section{Introduction}

Parkinson's disease (PD) age of onset is highly variable; however, approximately $20 \%$ of individuals with PD will be diagnosed before the age of 65 , with a reported prevalence rate of 128 per 100,000 in that age group [1-3]. Since some PD patients are employed, consumption of direct medical costs, and indirect costs due to productivity losses and time lost to work, are of concern.

PD progression has been classified by the five-stage Hoehn and Yahr (H\&Y) scale [4]. The time from onset to $\mathrm{H} \& \mathrm{Y}$ stage 5 has been estimated to be between 6 and 40 years [5]. Healthcare costs, productivity, quality of life and treatment vary by patients' disease stage, with evidence that productivity loss and medical resource consumption is greatest in the later stages of the disease [6-10].

The objective of the research described in this paper is to document the excess costs to payers for patients with PD, by degree of disease progression. To achieve this goal, the paper describes the results of an analysis of the excess costs incurred by patients with a diagnosis of PD, in comparison with those of other patients with the same demographic profile. In this way, the study will allow payers to have a better understanding of the incremental costs of PD disease progression, which will be useful as treatments relevant to a patient's stage of PD enter the market.

While prior analyses of PD have looked at a population aged 65 years and over, insured under the federally administered Medicare program, little published research has focused on privately insured PD patients in the USA, who are predominantly under the age of 65 years [10]. Furthermore, most assessments of the economic burden of PD have used short-term data from clinical trials or crosssectional studies [9, 11, 12], with cost estimates reflecting average costs over the entire course of PD; this method potentially masks the heterogeneity in costs over the course of disease progression. There have been a few exceptions, but these studies either used a small sample size [13], focused on comorbidity cost ratios instead of excess costs [14], or used longitudinal costs by $\mathrm{H} \& \mathrm{Y}$ stage from European data [7, 15-17]. These findings may not translate to the American healthcare landscape.

In this analysis, we used claims data to estimate direct (i.e. payments to providers by insurers for healthcare expenditures) costs related to excess healthcare resource consumption by PD patients under the age of 65 years at three different levels of disability, meant to estimate costs of disease as a function of progression. We also examined indirect (i.e. workloss costs borne by employers for lost work time due to disability and visits for medical care) costs in terms of PD-related absentee days and disability days for a subset of newly diagnosed patients.

\section{Data and Methods}

\subsection{Data and Study Design}

Data for this retrospective analysis were obtained from a de-identified administrative claims database of more than 12 million enrollees (i.e. employees, retirees, spouses and dependents) from 55 large, self-insured companies in the USA from different geographic regions and industries. Enrollees were eligible to receive medical services from 1 January 1999 through 31 March 2009. The database included eligibility data, claims for healthcare services (e.g. medical, prescription drug, long-term care [LTC]) for all enrollees, and disability claims for employees in 27 of the 55 companies. Eligibility data included monthly insurance enrollment, and age, gender and geographic region of residence. Medical claims included dates of service, International Classification of Diseases, Ninth Revision, Clinical Modification (ICD-9-CM) diagnosis codes, procedure codes and provider payments. Prescription drug claims contained National Drug Codes, fill dates and pharmacy payments. Because these are self-insured companies, payments represented costs to employers. Disability claims contained dates of disability and employer disability payments.

\subsection{Newly Diagnosed Cohort}

Newly diagnosed patients (Table 1) were continuously enrolled in the employer database from 12 months prior to (the baseline period) and 12 months following the index date (study year 1), defined as the first diagnosis of PD (ICD9-CM: 332.0) or first prescription of an anti-Parkinsonian drug (carbidopa or levodopa), whichever occurred first in claims. Anti-Parkinsonian drugs were identified as such based on Generic Product Identifier and American Hospital Formulary Service codes [18, 19, 20]. Patients were required to have evidence of PD (i.e. either two diagnoses of PD on different days or one diagnosis for PD and one prescription of carbidopa or levodopa) and be aged 18-64 years. To exclude patients with secondary PD or advanced disease, following prior methodology, patients were excluded with evidence of falls, treatment with anti-psychotics before the index date, or any conditions that could manifest like PD (i.e. Parkinsonism [ICD-9-CM: 332 or 332.1], dementia, Alzheimer's disease, schizophrenia, bipolar disorder or psychosis), claims for an ambulatory assistance device (AAD; 
Table 1 Cohort definitions

\begin{tabular}{|c|c|c|c|}
\hline Cohort & Disability level & Purpose & Index date \\
\hline Newly diagnosed cohort & At first diagnosis & $\begin{array}{l}\text { To determine the cost of newly } \\
\text { diagnosed PD pts }\end{array}$ & $\begin{array}{l}\text { Date of first PD diagnosis (ICD-9 code } \\
\text { 332.0), with washout for conditions } \\
\text { indicating delayed or wrong diagnosis }\end{array}$ \\
\hline PDAAD cohort & At first use of an $\mathrm{AAD}$ & $\begin{array}{l}\text { To determine the cost of PD pts } \\
\text { at the first sign of progression } \\
\text { to significant mobility } \\
\text { limitations }\end{array}$ & $\begin{array}{l}\text { First claim of walker or wheelchair ( } 2010 \\
\text { HCPCS codes) following first claim of } \\
\text { PD, with no prior claim of skilled } \\
\text { nursing }\end{array}$ \\
\hline PDINST cohort & At first institutionalization & $\begin{array}{l}\text { To determine the cost of PD pts } \\
\text { at the first sign of requiring } \\
\text { constant nursing care }\end{array}$ & $\begin{array}{l}\text { First claim of a nursing home, extended- } \\
\text { care facility, or skilled nursing facility } \\
\text { following first claim of PD }\end{array}$ \\
\hline
\end{tabular}

$A A D$ ambulatory assistance device, HCPCS Healthcare Common Procedure Coding System, ICD-9 International Classification of Diseases - 9th revision, $P D$ Parkinson's disease, PDAAD PD and ambulatory assistance device, PDINST PD and institutionalization, pts patients

wheelchair or walker in the durable medical equipment files) or LTC (skilled nursing facility, extended-care facility or nursing home) in the year prior to or following the index diagnosis [10]. Patients were followed from diagnosis for 3 years or until loss of eligibility, death, age 65 or loss of follow-up (through 31 March 2009).

\subsection{Parkinson's Disease and Ambulatory Assistance Device (PDAAD)}

Selection into the PD and ambulatory assistance device users (PDAAD) cohort was based on evidence of PD and an initial claim for a wheelchair or walker (index date) following a PD diagnosis, with no prior claim for LTC, to exclude more disabled patients (Table 1). Patients were also required to have 12 months of eligibility prior to (the baseline period) and following (study year 1) the index date, and were followed for 1 study year.

\subsection{PD and Institutionalization (PDINST)}

Patients with evidence of PD were selected into the PD and institutionalization (PDINST) cohort if they had at least one claim for LTC (index date) following a PD diagnosis (Table 1). Patients were also required to have 12 months of eligibility prior to (the baseline period) and following (study year 1) the index date, and were followed for 1 year.

Patients with PD were divided into three groups based on level of disease progression. While some patients are included in several of the cohorts, they were only eligible for inclusion in each cohort based on their chronologic progression, so that cost estimates reflect disease progression over time.

\subsection{Matched Non-PD Control Groups}

Control patients with no claims for PD, but who met the same eligibility requirements as the PD patients, were matched to PD patients based on age, gender and geographic region. In the newly diagnosed cohort, controls were matched $10: 1$ to PD patients, and in the PDAAD and PDINST cohorts, controls were matched 20:1 to PD patients by randomly matching patients without evidence of PD to each PD patient based on gender, age and geographic region. This straightforward demographic approach to matching is appropriate because our goal is to consider costs at different degrees of disease progression. We are not seeking to estimate costs for patients with similar comorbidity profiles (for example, through propensity-score matching) as one might do if the goal was to compare the effectiveness of different treatments.

\subsection{Outcomes}

Baseline characteristics included demographic information such as age, gender and Charlson Comorbidity Index [21], as well as comorbidities of PD identifiable in medical claims. Direct (healthcare) costs were based on reimbursed (paid) amounts by third-party payers and calculated annually for the baseline and study years for each cohort. Excess direct costs were calculated as average PD cohort costs minus non-PD control costs.

Indirect (workloss) costs were measured among the patients considered actively employed at baseline in the subset of companies with disability data. Medically related absenteeism was based on claims occurring during business days (e.g. Monday through Friday) as well as the waiting period in advance of a short-term disability episode, which was reported for each patient (e.g. 5 days of work missed due to illness). In instances with missing waiting period information, the most commonly observed waiting period at the particular company was used. Inpatient days or emergency department visits were considered as full days, and outpatient/other visits were considered as half-days of work loss. Medically related absenteeism costs were calculated based on employees' daily wage rates multiplied by 
their absenteeism days. Annual earnings were included in the database (daily wages were computed by dividing each patient's annual earnings by 261 days). Where annual earnings were not available, the mean annual earned amount for employees in that company was used. Disability costs were based on disability payments made by employers. Excess indirect costs were calculated as average PD cohort costs minus non-PD control costs.

\subsection{Statistical Methods}

Comorbidities were compared in the baseline period using Chi-square tests. Costs were compared using Wilcoxon rank sum tests. Direct and indirect costs were inflation-adjusted to year 2010 values based on the medical care and wage compensation components of the Consumer Price Index (average daily exchange rate for 2010: $\$ \mathrm{US} 1=€ 0.755$ ).

\section{Results}

\subsection{Baseline Characteristics}

A sample of $781 \mathrm{PD}$ patients and 7,810 matched controls were selected for the newly diagnosed cohort (Table 2), and samples of 214 and 156 PD patients, and 4,280 and 3,120 matched controls met criteria for the PDAAD and PDINST cohorts, respectively (Table 2). The newly diagnosed cohort was $37 \%$ female, with an average age of 56 years. Newly diagnosed PD patients had more comorbidities than controls at baseline. Patients in the PDAAD and PDINST cohorts were slightly older, at 58 and 59 years, and 43 and $47 \%$ were female. Among the PDAAD and PDINST cohorts, PD patients had significantly higher rates of comorbidities than controls.

\subsection{Direct Healthcare Costs}

Among the newly diagnosed PD patients, direct costs amounted to $\$$ US7,322 (Table 3) in the year prior to diagnosis, which was $\$ \mathrm{US} 2,820$ (i.e. excess costs) higher than the non-PD control group costs $(p<0.001)$. In study year 1 , the excess direct cost difference increased to \$US4,072 $(p<0.001)$. By year 3 for those who did not drop out of the sample ( $N=357$ PD patients), excess direct costs increased to $\$ \mathrm{US5}, 553$. The average annual growth rate of excess direct medical costs was $25.3 \%$ from the baseline year to year 3 ; from study year 1 (post diagnosis) to study year 3, costs increased $16.7 \%$ annually.

The distribution of the healthcare costs of the newly diagnosed patients was assessed in study year 1 (Table 4). PD patients had higher inpatient, emergency department, outpatient and prescription drug costs than did controls $(p<0.001)$. Average costs of outpatient services were \$US4,668, which included costs for physician consultations, physical therapy visits and other care delivered in a physician's office, clinic or outpatient hospital setting, and accounted for the largest source of direct healthcare costs

Table 2 Baseline characteristics

\begin{tabular}{|c|c|c|c|c|c|c|c|c|c|c|c|c|}
\hline & \multicolumn{4}{|c|}{ Newly diagnosed cohort } & \multicolumn{4}{|c|}{ PDAAD cohort } & \multicolumn{4}{|c|}{ PDINST cohort } \\
\hline & \multicolumn{2}{|c|}{$\begin{array}{l}\mathrm{PD} \\
N=781\end{array}$} & \multicolumn{2}{|c|}{$\begin{array}{l}\text { Control } \\
N=7,810\end{array}$} & \multicolumn{2}{|c|}{$\begin{array}{l}\mathrm{PD} \\
N=214\end{array}$} & \multicolumn{2}{|c|}{$\begin{array}{l}\text { Control } \\
N=4,280\end{array}$} & \multicolumn{2}{|c|}{$\begin{array}{l}\mathrm{PD} \\
N=156\end{array}$} & \multicolumn{2}{|c|}{$\begin{array}{l}\text { Control } \\
N=3,120\end{array}$} \\
\hline \multicolumn{13}{|l|}{ Baseline matched characteristics } \\
\hline Female & 286 & $36.6 \%$ & 2,860 & $36.6 \%$ & 92 & $43.0 \%$ & 1,840 & $43.0 \%$ & 74 & $47.4 \%$ & 1,480 & $47.4 \%$ \\
\hline Age (mean, SD) & 56 & $(6)$ & 56 & $(6)$ & 58 & $(6)$ & 58 & (6) & 59 & (4) & 59 & (4) \\
\hline \multicolumn{13}{|c|}{ Baseline comorbidities and comorbidities of PD } \\
\hline $\begin{array}{l}\text { Charlson comorbidity index } \\
\text { (mean, SD) }\end{array}$ & $0.57 *$ & $(1.21)$ & 0.38 & $(1.00)$ & $1.43^{*}$ & $(1.89)$ & 0.41 & $(1.02)$ & $2.13 *$ & $(2.41)$ & 0.47 & $(1.12)$ \\
\hline Mental disorders & $95^{*}$ & $12.2 \%$ & 637 & $8.2 \%$ & $94 *$ & $43.9 \%$ & 374 & $8.7 \%$ & $89^{*}$ & $57.1 \%$ & 321 & $10.3 \%$ \\
\hline $\begin{array}{l}\text { Diseases of the nervous system and } \\
\text { sense organs }\end{array}$ & $387 *$ & $49.6 \%$ & 1,711 & $21.9 \%$ & $207 *$ & $96.7 \%$ & 1,025 & $23.9 \%$ & $143^{*}$ & $91.7 \%$ & 854 & $27.4 \%$ \\
\hline $\begin{array}{l}\text { Symptoms, signs and ill-defined } \\
\text { conditions }\end{array}$ & $542 *$ & $69.4 \%$ & 3,083 & $39.5 \%$ & $188^{*}$ & $87.9 \%$ & 1,759 & $41.1 \%$ & $144^{*}$ & $92.3 \%$ & 1,366 & $43.8 \%$ \\
\hline Neuropsychiatric disorders & $39 *$ & $5.0 \%$ & 191 & $2.4 \%$ & $44 *$ & $20.6 \%$ & 124 & $2.9 \%$ & $45^{*}$ & $28.8 \%$ & 117 & $3.8 \%$ \\
\hline Falls & $0^{*}$ & $0.0 \%$ & 850 & $10.9 \%$ & $89 *$ & $41.6 \%$ & 488 & $11.4 \%$ & $75^{*}$ & $48.1 \%$ & 368 & $11.8 \%$ \\
\hline Sleep disorders & $56^{*}$ & $7.2 \%$ & 282 & $3.6 \%$ & $37 *$ & $17.3 \%$ & 149 & $3.5 \%$ & $23^{*}$ & $14.7 \%$ & 109 & $3.5 \%$ \\
\hline Autonomic dysfunction & $242 *$ & $31.0 \%$ & 1,814 & $23.2 \%$ & $123 *$ & $57.5 \%$ & 1,042 & $24.3 \%$ & $96^{*}$ & $61.5 \%$ & 788 & $25.3 \%$ \\
\hline
\end{tabular}

* Significant at $p<0.01$ via a chi-square test for categorical variables, Wilcoxon rank sum tests for continuous variables

$P D$ Parkinson's disease, PDAAD PD and ambulatory assistance device, PDINST PD and institutionalization, SD standard deviation 
Table 3 Total direct costs by cohort (\$US, year 2010 values)

\begin{tabular}{|c|c|c|c|c|c|c|c|c|}
\hline & \multirow{2}{*}{$\begin{array}{l}\text { PD pts } \\
N\end{array}$} & \multicolumn{2}{|c|}{ Total direct cost } & \multirow{2}{*}{$\begin{array}{l}\text { Control pts } \\
N\end{array}$} & \multicolumn{2}{|c|}{ Total direct cost } & \multicolumn{2}{|c|}{ Excess direct costs } \\
\hline & & Mean & SD & & Mean & SD & Mean & $p$ value \\
\hline \multicolumn{9}{|l|}{ Newly diagnosed cohort } \\
\hline Baseline year (pre-diagnosis) & 781 & 7,322 & 18,129 & 7,810 & 4,502 & 12,895 & 2,820 & $<0.001$ \\
\hline Study year 1 & 781 & 9,175 & 17,006 & 7,810 & 5,103 & 16,340 & 4,072 & $<0.001$ \\
\hline Study year 2 & 509 & 9,948 & 17,248 & 5,090 & 5,164 & 14,480 & 4,785 & $<0.001$ \\
\hline Study year 3 & 357 & 10,706 & 25,639 & 3,570 & 5,153 & 12,745 & 5,553 & $<0.001$ \\
\hline \multicolumn{9}{|l|}{ PDAAD cohort } \\
\hline Study year 1 & 214 & 31,800 & 99,695 & 4,280 & 5,333 & 14,499 & 26,467 & $<0.001$ \\
\hline \multicolumn{9}{|l|}{ PDINST cohort } \\
\hline Study year 1 & 156 & 43,506 & 63,125 & 3,120 & 6,096 & 18,779 & 37,410 & $<0.001$ \\
\hline
\end{tabular}

PD Parkinson's disease, PDAAD PD and ambulatory assistance device, PDINST PD and institutionalization, $p t s$ patients, $S D$ standard deviation

(50.9\%) on average, followed by prescription drugs (\$US2,872, or $31.3 \%$ of direct healthcare costs).

The more advanced PDAAD patients had \$US26,467 in costs in excess of their controls in study year $1(p<0.001)$. Inpatient care was the largest source of costs for PDAAD patients, which represented on average $\$$ US14,111 in direct healthcare costs or $44.4 \%$ of the total, followed by outpatient services (\$US9,184, or $28.9 \%$ of the total) and prescription drugs (U\$US7,228, or $22.7 \%$ of the total). Among the PDINST cohort, PD patient costs were \$US37,410 more than those of controls $(p<0.001)$ in study year 1 . Inpatient care was also the largest cost for the PDINST cohort (\$US15,026), or about $34.5 \%$ of total costs. Other key drivers for the PDINST cohort included outpatient services (26.5\% of total costs), prescription drugs $(20.1 \%$ of total costs) and LTC costs (16.2\% of total costs).

\subsection{Medically Related Absenteeism and Disability Costs}

A sample of 173 newly diagnosed patients who also had disability and medically related absenteeism data were matched to a control group $(N=1,730)$ (Table 5). In the year after diagnosis, disability costs for PD patients were \$US2,055, compared with \$US89 for the controls $(p<0.05)$. Average medically related absenteeism costs were \$US2,315 for PD patients and \$US971 for controls $(p<0.05)$. The excess indirect (workloss) cost was $\$ \mathrm{US3}, 311(p<0.05)$ in the year after initial diagnosis. In the year prior to diagnosis, excess indirect costs were also significantly higher in the PD group (\$US592; $p<0.05$ ). When considered as a proportion of direct and indirect costs in study year 1 for the newly diagnosed, these costs represented $32.3 \%$ of the total. When compared as a proportion of total excess costs in this study, indirect costs represented about $44.8 \%$ of the total. The PDAAD
$(N=9)$ and PDINST $(N=5)$ samples were not large enough for indirect cost analysis.

\section{Discussion}

While PD is often associated with the elderly due to its long disease course, a substantial proportion of incident cases occur in the patient population aged under 65 years [3]. This is the first analysis that we are aware of that estimates the costs of these patients using data from a commercially insured patient population in the USA. In 2010, approximately $59 \%$ of the US population aged 18-64 years had private health insurance coverage obtained through the workplace, resulting in a large unmet gap in the information on the burden of PD in this patient population [22]. Empirical examination of progression-related costs associated with PD can inform the expected cost trajectory for patients, physicians, payers and employers. By comparing costs of the PD cohorts versus age-, gender- and regionmatched non-PD patients, excess costs were estimated, which are indicative of the resources that would be consumed due to PD as the disease progresses.

The costs in our data are relevant to patients, physicians and payers in the USA, but are primarily borne by employers, as the data represent claims from large companies that self-insure and thus pay for direct medical costs. These employers also bear the indirect costs of patients in terms of medically related absenteeism (e.g. as patients miss work due to, for example, neurology visits) and disability payments. These costs may be used to help payers understand the burden of PD in comparison with other diseases, to provide benchmarks and proxies for the average costs paid by third-party payers at various stages after PD diagnosis, and to estimate potential inputs into cost-effectiveness models for decision making. 


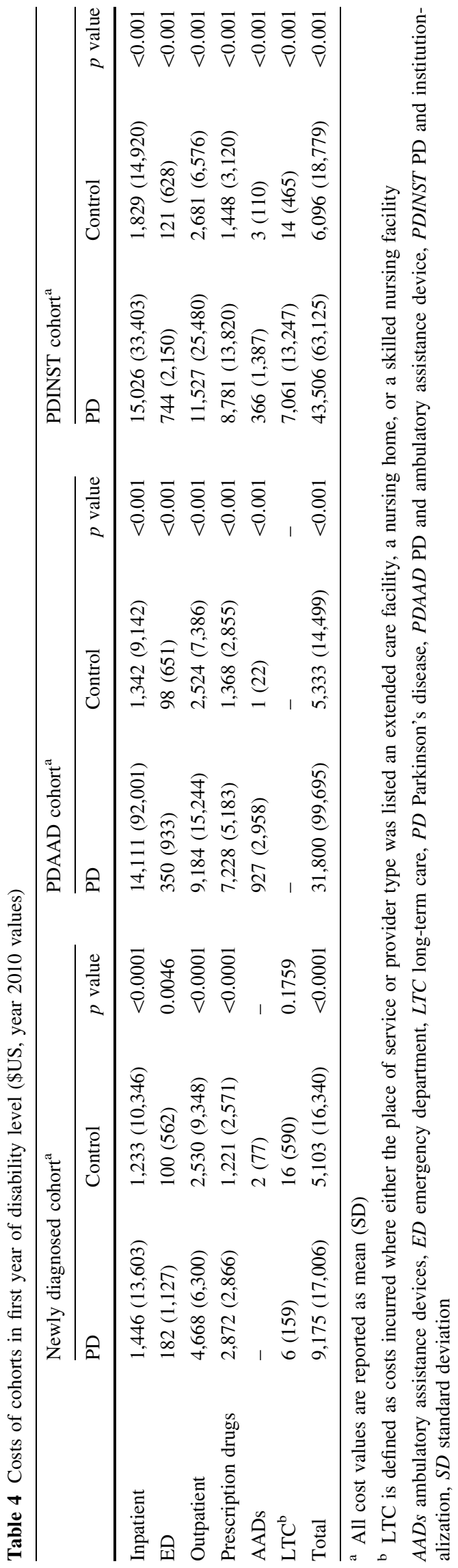

We found that excess costs related to PD are substantial and have a compound annual growth rate of $25 \%$ for the first 3 years after a patient is newly diagnosed. Excess costs begin in the year prior to diagnosis. Indirect costs account for more than one quarter of the total costs, and almost one half of excess costs, related to the newly diagnosed in their first year.

The disease course of PD is long, and characterizing the complete cost trajectory requires more than an analysis of the first 3 years after initial diagnosis. To approximate costs at key inflection points of the disease, we included patients from the point at which they were observed to require ambulatory assistance (given that international studies have shown that resource use increases at $\mathrm{H} \& \mathrm{Y}$ stages 3 and 4, when ambulation becomes difficult) [7] and when entering institutional care, where a plurality of PD costs occur [23].

The direct cost estimates are generally in line with Huse et al. [24], who used claims to estimate adjusted excess annual direct costs in a population with private insurance or Medicaid to be \$US14,075 (year 2010 values); however, they followed patients from first diagnosis, did not attempt to stratify patients by proxies for disease progression status, and also included patients under and over age 65 in their sample. Other research using the same cohort definitions in the Medicare patient population found lower excess costs for newly diagnosed patients (\$US2,481; year 2010 values) and the PDAAD cohort (\$US17,062; year 2010 values), but higher for PDINST (\$US44,862; year 2010 values) during the first study year [10]. The differences between the private payer and Medicare results could be due to a variety of factors, including differences in patient population (e.g. comorbidity burden of the PD patients and controls), physician uncertainty in diagnosis of older patients and benefit design differences.

Costs of patients with PD in the baseline and study periods were high for cohorts in all time periods, including the baseline period relative to the average privately insured patient, whose average annual spending in the USA was \$US4,000 (year 2010 values) [25]. Accordingly, the average costs for the three cohorts of PD patients range from 2.3 to 10.8 times the costs of the average privately insured patient. Findings also indicate that the direct cost burden of PD is comparable to estimates for chronic kidney disease amongst patients with comorbid hypertension (\$US8,975; year 2010 values) [26] or estimates for patients with cancer (\$US32,957 for prostate cancer to \$US130,150 for pancreatic cancer; year 2010 values) [27] in a private payer setting.

Claims data do not include clinical information on disease severity or health outcomes. Accordingly, the proxies used here for later stages of disability and progression are not clinically validated. While chart abstracts would be 
Table 5 Indirect costs (medically related absenteeism and disability costs) for newly diagnosed patients (\$US, year 2010 values)

\begin{tabular}{|c|c|c|c|c|c|c|c|c|c|c|c|}
\hline \multirow{3}{*}{$\begin{array}{l}\text { Newly diagnosed cohort with } \\
\text { disability data }\end{array}$} & \multicolumn{5}{|c|}{ PD patients } & \multicolumn{5}{|c|}{ Control patients } & \multirow{3}{*}{$\begin{array}{l}\text { Excess indirect costs } \\
\text { Mean } \\
{[I]=[(A+C)-} \\
(E+G)]\end{array}$} \\
\hline & \multirow[t]{2}{*}{$N$} & \multicolumn{2}{|c|}{ Disability cost } & \multicolumn{2}{|c|}{$\begin{array}{l}\text { Medically } \\
\text { related } \\
\text { absenteeism } \\
\text { cost }\end{array}$} & \multirow[t]{2}{*}{$N$} & \multicolumn{2}{|c|}{$\begin{array}{l}\text { Disability } \\
\text { cost }\end{array}$} & \multicolumn{2}{|c|}{$\begin{array}{l}\text { Medically } \\
\text { related } \\
\text { absenteeism } \\
\text { cost }\end{array}$} & \\
\hline & & $\begin{array}{l}\text { Mean } \\
{[A]}\end{array}$ & $\begin{array}{l}\text { SD } \\
{[B]}\end{array}$ & $\begin{array}{l}\text { Mean } \\
{[C]}\end{array}$ & $\begin{array}{l}\text { SD } \\
{[D]}\end{array}$ & & $\begin{array}{l}\text { Mean } \\
{[E]}\end{array}$ & $\begin{array}{l}\text { SD } \\
{[F]}\end{array}$ & $\begin{array}{l}\text { Mean } \\
{[G]}\end{array}$ & $\begin{array}{l}\text { SD } \\
{[H]}\end{array}$ & \\
\hline Baseline year & 173 & $405^{*}$ & 2,787 & $1,315^{*}$ & 1,775 & 1,730 & $284^{*}$ & 3,331 & $845^{*}$ & 1,711 & $592 *$ \\
\hline Year 1 & 173 & $2,055^{*}$ & 8,162 & $2,315^{*}$ & 3,011 & 1,730 & $89 *$ & 981 & $971^{*}$ & 1,830 & $3,311^{*}$ \\
\hline
\end{tabular}

Costs inflation adjusted by the Consumer Price Index for Urban Wage Earners and Clerical Workers (CPI-W)

* Indicates $[A]$ vs. $[E]$ and $[C]$ vs. $[G]$ and $[I]$ vs. 0 are significantly different at $p<0.05$

$P D$ Parkinson's disease, $S D$ standard deviation

required to validate PD progression staging, claims data offer large, longitudinal, economical samples. Our advanced samples likely contain higher proportions of patients with 'early-onset' PD, and we likely exclude many patients who have never been appropriately diagnosed [28]. Therefore, underlying differences in the patient characteristics of each cohort should be considered when comparing results from the different cohorts. As patients in the PDAAD and PDINST cohorts are older and have more comorbidities than newly diagnosed patients, this may contribute to the excess resource use and costs associated with PD. From a payer perspective, such differences in underlying patient characteristics are an important part of the package of care delivered to PD patients at each stage of the disease. However, as the analysis did not control for comorbidities, some of the estimated excess costs may be due to comorbidities that are not directly related to PD. Finally, when using claims, we rely on data including only patients engaging with the healthcare system. Many with PD may not engage with the system, and would therefore be excluded, which could increase our estimates in the PD group. However, this is likely more true for the control patient cohorts, such that our excess cost estimates may be underestimated. Further, this analysis focuses on a privately insured patient population and therefore, costs may not be generalizable to other patient populations. In addition, costs of care may be heterogeneous within each cohort, as some patients may not get timely diagnosis of PD or optimal therapeutic dosing [29, 30].

Research has indicated that the rate of dropout from employment is higher among PD patients than non-PD controls [31], so it seems reasonable to infer that patients with more severe PD would have a higher propensity to drop out of employment or private insurance coverage than the average PD patient. Further research on this topic is warranted. Such survivor bias would most affect the advanced cohorts, as the most resource-intensive patients drop out of the sample, causing lower cost estimates. However, from a private payer perspective, survivor bias is less relevant than it would be for other perspectives; as privately insured patients reach the age of 65 , costs incurred with disease progression will be borne by Medicare. The cost estimates presented here should be considered accordingly. Furthermore, we were not able to follow stable samples of advanced cases longitudinally in our private payer claims data, likely due to excess withdrawal from private insurance for these patients.

There are additional areas of future research that may be important. First, this analysis excludes components of indirect costs, including those relevant to employers and employees, such as costs related to early retirement, presenteeism, lack of progress in the patient and caregiver's career or inability to gain employment. The analysis also excludes costs to patients and society such as caregiver burden, 'alternative' medicine, home modifications or childcare, which can be significant $[9,10]$. These are important and potentially large elements of costs, and future research could estimate them through the use of patient or caregiver surveys. Second, an analysis that focuses on treatment patterns for patients with PD and associated costs in this patient population may be an area for future research. Third, future research may estimate the overall budget impact for private payers associated with treating patients with PD.

\section{Conclusions}

Costs borne by employers related to PD are substantial and grow over time. Indirect costs represent a substantial portion of total costs. Direct costs were highest in more advanced PD patients. Prolonging the time until patients experience advanced PD may result in substantial cost containment for employers. 
Acknowledgments This research has been financially supported by Teva Pharmaceuticals. The authors independently conducted all analyses and wrote the manuscript. The authors controlled the decision to write and submit the manuscript for publication. EG is an employee of Teva Pharmaceuticals. AK, MD and HGB are employees of Analysis Group, Inc. SJJ was an employee of Analysis Group, Inc. at the time of this research. JCH was an employee of Teva Pharmaceuticals at the time of this research. ADS was an employee of University of Pennsylvania at the time of this research. ADS received consulting fees for the work from Analysis Group, Inc. under a contract with Teva Pharmaceuticals.

Authors' contributions SJJ, HGB, EG, JCH and ADS designed the study and played a key role in interpreting the data analysis and drafting the manuscript. SJJ, HGB, AK, MD and ADS played a key role in the study conduct and data collection for the analysis used in this manuscript. SJJ is the guarantor of the paper.

Open Access This article is distributed under the terms of the Creative Commons Attribution Noncommercial License which permits any noncommercial use, distribution, and reproduction in any medium, provided the original author(s) and the source are credited.

\section{References}

1. Dorsey ER, Constantinescu R, Thompson JP, et al. Projected number of people with Parkinson disease in the most populous nations, 2005 through 2030. Neurology. 2007;68(5):384-6.

2. Huse DM, Castelli-Haley J, Orsini LS, et al. Patterns of initial pharmacotherapy for Parkinson's disease in the United States. J Geriatr Psychiatry Neurol. 2006;19:91-7.

3. Van Den Eeden SK, Tanner CM, Bernstein AL, et al. Incidence of Parkinson's disease: variation by age, gender, and race/Ethnicity. Am J Epidemiol. 2003;157(11):1015-22.

4. Hoehn MM, Yahr MD. Parkinsonism: onset, progression and mortality. Neurology. 1967;17:427-42.

5. Poewe W. The natural history of Parkinson's disease. J Neurol. 2006; 253Suppl7:VII2-6.

6. Schrag A, Jahanshahi M, Quinn N. What contributes to quality of life in patients with Parkinson's disease? J Neurol Neurosurg Psychiatry. 2000;69:308-12.

7. Keranen T, Kaakkola S, Sotaniemi K, et al. Economic burden and quality of life impairment increase with severity of PD. Parkinsonism Relat Disord. 2003;9:163-8.

8. Schenkman M, Zhu CW, Cutson TM, et al. Longitudinal evaluation of economic and physical impact of Parkinson's disease. Parkinsonism Relat Disord. 2001;8:41-50.

9. Whetten-Goldstein K, Sloan F, Kulas E, et al. The burden of Parkinson's disease on society, family, and the individual. J Am Geriatr Soc. 1997;45:844-9.

10. Kaltenboeck A, Johnson SJ, Davis MR, et al. Direct costs and survival of Medicare beneficiaries with early and advanced Parkinson's disease. Parkinsonism Relat Disord. 2012;18(4):321-6.

11. Rubenstein LM, DeLeo A, Chrischilles EA. Economic and health-related quality of life considerations of new therapies on Parkinson's disease. Pharmacoeconomics. 2001;19:729-52.

12. Dodel RC, Berger K, Oertel WH. Health-related quality of life and healthcare utilization in patients with Parkinson's disease: impact of motor fluctuations and dyskinesias. Pharmacoeconomics. 2001;19:1012-38.

13. Leibson CL, Long KH, Maraganore DM, et al. Direct medical costs associated with Parkinson's disease: a population-based study. Mov Disord. 2006;21:1864-71.

14. Pressley JC, Louis ED, Tang MX, et al. The impact of comorbid disease and injuries on resource use and expenditures in Parkinsonism. Neurology. 2003;60(1):87-93.

15. McCrone P, Allcock LM, Burn DJ. Predicting the cost of Parkinson's disease. Mov Disord. 2007;22(6):804-12.

16. Dodel RC, Singer M, Köhne-Volland R, et al. The economic impact of Parkinson's disease: an estimation based on a 3-month prospective analysis. Pharmacoeconomics. 1998;14(3):299-312.

17. LePen C, Wait S, Moutard-Martin F, et al. Cost of illness and disease severity in a cohort of French patients with Parkinson's disease. Pharmacoeconomics. 1999;16:59-69.

18. Master Drug Data Base (MDDB(r)) v2.5 Documentation Manual. Indianapolis, IN: Wolters Kluwer Health, Inc.; 2005

19. Master Drug Data Base v2.5 (MDDB(r)). U.S. Food and Drug Administration (2010). http://www.medi-span.com/master-drugdatabase.aspx. Accessed 7 September 2010

20. National Drug Code Query (2010). http://www.accessdata.fda. gov/scripts/cder/ndc/activeingredient.cfm. Accessed 15 July 2010

21. Deyo RA, Cherkin DC, Ciol MA. Adapting a clinical comorbidity index for use with ICD-9-CM administrative databases. J Clin Epidemiol. 1992;45(6):613-9.

22. National Center for Health Statistics. Health, United States, 2011: With Special Feature on Socioeconomic Status and Health. Hyattsville, MD. 2012. http://www.cdc.gov/nchs/data/hus/hus11. pdf\#139. Accessed April 192013.

23. Noyes K, Liu H, Yue L, et al. Economic burden associated with Parkinson's disease on elderly Medicare beneficiaries. Mov Disord. 2006;21:362-72.

24. Huse DM, Schulman K, Orsini L, et al. Burden of illness in Parkinson's disease. Mov Disord. 2005;20(11):1449-54.

25. Bundorf MK, Royalty A, Baker LC. Health care cost growth among the privately insured. Health Aff (Millwood). 2009;28:1294-304. (Costs inflation adjusted to 2010 dollars using the Consumer Price Index for medical care).

26. Laliberté F, Bookhart BK, Vekeman F, et al. Direct all-cause health care costs associated with chronic kidney disease in patients with diabetes and hypertension: a Managed Care Perspective. J Manag Care Pharm. 2009;15:312-22. (Costs inflation adjusted to 2010 dollars using the Consumer Price Index for medical care).

27. Chang S, Long SR, Kutikova L, et al. Estimating the cost of cancer: results on the basis of claims data analyses for cancer patients diagnosed with seven types of cancer during 1999 to 2000. J Clin Oncol. 2004;22:3524-30. (Costs inflation adjusted to 2010 dollars using the Consumer Price Index for medical care).

28. Chaudhuri KR, Healy DG, Schapira AH. Non-motor symptoms of Parkinson's disease: diagnosis and management. Lancet Neurol. 2006;5(3):235-45.

29. Müller T, Woitalla D. Quality of life, caregiver burden and insurance in German patients with Parkinson's disease. Eur J Neurol. 2010;17(11):1365-9.

30. Müller T, Voß B, Hellwig K, Przuntek H. Treatment benefit and daily drug costs in Parkinson's disease clinics. CNS Drugs. 2004;18(2):105-11.

31. Johnson S, Davis M, Kaltenboeck A, et al. Early retirement and income loss in patients with early and advanced Parkinson's disease. Appl Health Econ Health Pol. 2011;9(6):367-76. 